\title{
Use of cluster analysis to describe desaturator phenotypes in COPD: correlations between pulmonary function tests and nocturnal oxygen desaturation
}

Domenico Maurizio

Toraldo'

Francesco De Nuccio

Annarita Gaballo'

Giuseppe Nicolardi ${ }^{2}$

'A Galateo Lung Disease Hospital, Regional Service Puglia, San Cesario di Lecce, ${ }^{2}$ Laboratory of Human Anatomy, Department of Biological and Environmental Sciences and Technologies, University of Lecce, Lecce, Italy
Correspondence: Domenico Maurizio Toraldo

via AC Casetti 2, 73100 Lecce, Italy

$\mathrm{Tel}+390832349890$

$\mathrm{Fax}+390832349890$

Email d.torald@tin.it
This article was published in the following Dove Press journal:

International Journal of COPD

8 November 2011

Number of times this article has been viewed

Background: Significant heterogeneity of clinical presentation and disease progression exists within chronic obstructive pulmonary disease (COPD). Although forced expiratory volume in 1 second $\left(\mathrm{FEV}_{1}\right)$ inadequately describes this heterogeneity, a clear alternative has not emerged. This article discusses and refines the concept of phenotyping desaturators in COPD and shows a possible pattern which could be used as a framework for future research.

Recent findings: COPD is a complex condition with pulmonary and extrapulmonary manifestations. We suggest that COPD phenotypes should be associated with clinically meaningful outcomes. The innovation of COPD phenotyping is defined as COPD desaturators. Sleep-related hypoxemia and hypercapnia are well recognized in COPD and the development of systemic inflammation during sleep. These sleep-related changes predispose to nocturnal cardiac arrhythmias, pulmonary hypertension, and possibly death, particularly during acute exacerbations.

Conclusion: A more focused definition makes possible a classification of patients into two distinct subgroups for both clinical and research purposes. Establishing a common language for future research will facilitate our understanding and management of such diseases. Even if different treatment strategies have different outcomes for these groups, we will have confirmation, or otherwise, of the clinical value of cluster analysis. This knowledge could lead to pharmacological treatment and other interventions directed to specific phenotypic groups.

Keywords: phenotypes, chronic obstructive pulmonary disease, desaturator, nocturnal hypoxemia, systemic inflammation, intermittent hypoxia

\section{Introduction}

Chronic obstructive pulmonary disease (COPD) is defined as a "preventable" but treatable disease with significant extrapulmonary effects that may contribute to its severity in individual patients. ${ }^{1}$ However, COPD is a complex, multicomponent, heterogeneous disease, the clinical, functional and radiological presentation of which varies greatly from patient to patient, even though the degree of airflow limitation may be similar. ${ }^{1,2}$ The current classification of airways disorders is imprecise, with an overlap of phenotypes (eg, asthma, chronic bronchitis, and emphysema), resulting in difficulties in differentiating between these disorders.

The prevalence, distribution, and interrelationships of the main clinical and functional manifestations of the disease in a large, well-characterized, and controlled population of patients is lacking. Comorbidities such as chronic heart failure, cardiovascular disease, depression, diabetes, muscle wasting, weight loss, lung cancer, and 
osteoporosis, are frequently found in patients with COPD, and are considered to be part of the commonly prevalent nonpulmonary sequelae of the disease. ${ }^{3,4}$ Sleep-disordered breathing and COPD are among the most common pulmonary diseases.

Cluster analysis is a collection of methods for defining groups of individuals based on measured characteristics, so they can be grouped according to their differences (or similarities) into clusters. This paper focuses on COPD and nocturnal hypoxemia, aiming at defining, through cluster analysis, a pattern of clinical variables that differentiate desaturator from nondesaturator patients and at identifying daytime variables that are predictive of nocturnal desaturation. This more focused description makes possible a classification of patients into distinct subgroups for both clinical and research purposes.

\section{Systemic inflammation in COPD}

Several studies have found markers of systemic inflammation, such as high-sensitivity C-reactive protein, to be higher in the blood of patients with COPD than in subjects without COPD. ${ }^{5,6}$ The question arises as to whether systemic inflammation is the result of a local inflammation spillover into the systemic compartments or a systemic component of COPD not necessarily related to local inflammatory processes in the lung. 7,8

As a point of interest, it should be noted that systemic inflammation has failed, so far, to show substantial correlations with airway obstruction, ${ }^{9,11}$ whereas at least some relationship has been reported between local inflammatory processes and airway obstruction. ${ }^{12,14}$ Markers of systemic inflammation have been shown to be elevated in the blood of patients with COPD when compared with control subjects without COPD. COPD is often accompanied by other chronic diseases associated with systemic inflammation, such as chronic heart failure, diabetes, and arteriosclerosis. ${ }^{15}$ Alternatively, increased blood levels of inflammatory mediators in patients may stem from extrapulmonary cells (circulating leukocytes, endothelium, or muscle cells). A particular problem in COPD patients with marked alveolar wall destruction is intermittent and continuous hypoxia. A significant inverse correlation between arterial oxygen tension $\left(\mathrm{PaO}_{2}\right)$, circulating tumor necrosis factor alpha, and soluble tumor necrosis factor receptor levels has been reported in patients with COPD. ${ }^{16}$ Similarly, a significant relationship between reduced oxygen delivery and tumor necrosis factor alpha levels in the peripheral circulation has been found, highlighting the role of nocturnal hypoxia in the tissue. ${ }^{17}$
It has been suggested that systemic inflammation may explain part of the heterogeneity of COPD phenotypes, such as loss of lean body mass and the higher prevalence of comorbid disorders, such as coronary heart disease, depression, and hypertension. Finally, this study reinforces the view that systemic inflammation is an important phenotypic feature of COPD. ${ }^{18}$ Future prospective studies should investigate whether these markers give important prognostic information in relation to disease progression and severity in COPD.

\section{Sleep in patients with COPD}

COPD alone can cause subjective and objective changes during sleep. When patients with chronic bronchitis or emphysema were surveyed across a broad range of symptoms, "sleep difficulties" were endorsed as occurring "almost always" or "always" in $43 \%$ of subjects (third most common, after dyspnea and fatigue). ${ }^{19}$ In addition to the diagnosis of COPD, the presence of COPD symptoms, such as cough, sputum production, and wheezing correlated strongly with difficulty in falling or staying asleep. ${ }^{20}$ Other investigations have objectively confirmed poor sleep quality, with decreased total sleep time and decreased sleep efficiency. ${ }^{21}$

A brief review of the normal changes in respiration that occur with sleep onset and the various sleep stages is useful for understanding the changes occurring during sleep in patients with COPD. In healthy subjects, minute ventilation drops from wakefulness to non-rapid eye movement (non-REM) sleep, and drops further during REM sleep (about 15\% compared with the awake value). ${ }^{22}$ Most of the drop in minute ventilation is due to a decrease in tidal volume not fully compensated by a concomitant increase in respiratory rate. There is a blunted ventilatory response to hypoxia and hypercapnia, again with the greatest changes during REM sleep. ${ }^{23}$ Sleep-related hypoventilation has been demonstrated in COPD, particularly during REM sleep, with associated oxygen desaturation. ${ }^{24}$ Nocturnal oxygen desaturation in COPD is likely to be the consequence of the combined effects of physiological hypoventilation during sleep. However, there is evidence that some patients with awake $\mathrm{PaO}_{2}$ levels in the mildly hypoxemic range can also develop clinically significant nocturnal oxygen desaturation, which may predispose to pulmonary hypertension. ${ }^{25}$ Finally, possible mechanisms responsible for this reduction include respiratory muscle hypotonia, cephalic displacement of the diaphragm, and a decrease in lung compliance. ${ }^{26}$ 


\section{Mechanisms of sleep-related breathing disturbances in COPD}

Sleep-related hypoventilation has been demonstrated in COPD, with associated oxygen desaturation particularly during REM sleep. ${ }^{27}$ There is a close relationship between the awake $\mathrm{PaO}_{2}$ and nocturnal oxygen saturation levels, ${ }^{28}$ although hypercapnia is associated with more pronounced nocturnal oxygen desaturation than normocapnia for any given level of waking oxygen saturation level. ${ }^{29}$

Nocturnal hypoxemia is defined as an oxygen saturation level $\leq 90 \%$ for at least 5 minutes, with a nadir oxygen saturation level of $\leq 85 \%$. Time in bed is defined as the time from the start to end of the recording. The percentage of total recording time is defined as time spent in bed - sleep latency + intrasleep wakefulness. The total recording time spent in bed with an oxygen saturation level $\leq 90 \%$ is defined as the $T_{90}$. The minimal total recording time required for satisfactory analysis of nocturnal recordings is 2 hours. In one study, COPD patients with a $\mathrm{T}_{90} \geq 30 \%$ and a nadir oxygen saturation level of $85 \%$ were defined as desaturators and the others as nondesaturators. ${ }^{30} \mathrm{COPD}$ desaturator patients may be identified by a clinical pattern of variables rather than by $\mathrm{T}_{90}$ alone, ie, $\mathrm{T}_{90}$, mean pulmonary artery pressure, and arterial carbon dioxide tension values, with the latter two variables being predictors of severity of nocturnal desaturation. Alveolar hypoventilation probably accounts for most of the oxygen desaturation. Becker et $\mathrm{al}^{31}$ measured minute ventilation during wakefulness, non-REM sleep, and REM sleep in normal subjects and in patients with COPD. The greater drop seen in minute ventilation in subjects with COPD may reflect increased dependence on accessory muscles that become hypotonic during sleep, particularly during REM sleep. An alternative explanation comes from the work of O'Donoghue et $\mathrm{al}^{132}$ who found an even greater drop in minute ventilation during non-REM sleep in hypercapnic COPD patients.

\section{Consequences of nocturnal oxygen desaturation in COPD}

The exact prevalence of pulmonary hypertension in patients with COPD is unclear. ${ }^{33}$ Pulmonary hypertension is a complication of advanced COPD observed in patients who show severe longstanding hypoxemia. Even if pulmonary hypertension is generally mild to moderate in most COPD patients, it may worsen markedly during acute exacerbations, sleep, and exercise, and these acute increases in pulmonary hypertension could facilitate the development of right heart failure. Diagnosis of pulmonary hypertension in COPD patients is difficult. The published studies differ not only in their definitions but also for conditions in which pulmonary hypertension has been reported (ie, rest, exercise, and exacerbation). According to the European Society Cardiology and European Respiratory Society, ${ }^{34}$ pulmonary hypertension is defined as an increase in mean pulmonary artery pressure $\geq 25 \mathrm{mmHg}$ at rest as assessed by right heart catheterization. The definition of pulmonary hypertension on exercise as a pulmonary artery pressure $\geq 30 \mathrm{mmHg}$ assessed by right heart catheterization is not supported by the published data, and healthy individuals can reach much higher values.

The incidence of pulmonary hypertension in COPD patients has been evaluated by Kessler et al, ${ }^{35}$ who performed a longitudinal study in 131 patients with COPD with serial right heart catheterization at baseline and then at follow-up (mean $6.8 \pm 2.9$ years). All subjects had normal mean pulmonary artery pressure at rest $(\leq 20 \mathrm{mmHg})$. They were divided into two groups according to the presence or absence of elevated mean pulmonary artery pressure with exercise $(\geq 30 \mathrm{mmHg}$ ), and $25 \%$ of patients developed pulmonary hypertension on follow-up that was mild by hemodynamic criteria (mean pulmonary artery pressure $26.8 \pm 6.6 \mathrm{mmHg}$ ). Subjects who showed elevated pulmonary hypertension with exercise were more likely to exhibit resting mean pulmonary artery pressure elevation at follow-up. The annual rate of progression was $+0.4 \mathrm{mmHg}$.

Nocturnal oxygen desaturation seems to contribute to the development of pulmonary hypertension, even in the absence of significant awake hypoxemia. ${ }^{36}$ REM-associated falls in oxygen saturation levels are associated with increases in pulmonary artery pressure during sleep that can be reversed by supplemental oxygen, although most COPD patients with sustained pulmonary hypertension are also hypoxemic during the daytime. Various arrhythmias have also been reported during episodes of nocturnal desaturation. ${ }^{37}$ These observations might help to explain why nocturnal oxygen desaturation is a marker of increased mortality, and why COPD patients are reported to die more frequently than expected at night. ${ }^{38}$

Tissue hypoxia is another mechanism that can contribute to systemic inflammation in COPD. In one clinical study ${ }^{19}$ it was shown that tumor necrosis factor alpha and its receptor levels were significantly higher in patients with COPD, and were correlated significantly with severity of arterial hypoxemia. These results suggest that arterial hypoxemia in COPD is associated with activation of the tumor necrosis factor alpha system in vivo. 
The systemic effects of inflammation may contribute significantly to not only the respiratory abnormalities, symptoms, and functional impairment (eg, exercise intolerance) associated with COPD but also to the marked changes in vasomotor and endothelial function seen in chronic pulmonary vascular disease. ${ }^{39}$ The nocturnal desaturation-reoxygenation sequence is a typical pattern coupled with the majority of respiratory events. This sequence, defining intermittent hypoxia, leads to oxidative stress, with production of reactive oxygen species..$^{40}$ Hypoxia-induced pulmonary vasoconstriction is a protective response to keep the ventilation-perfusion ratio at an optimum level by shunting blood away from hypoxemic areas. The traditional hypoxic model of pulmonary hypertension is based on the hypothesis that chronic hypoxia initiates vascular remodeling, leading to permanent changes in the pulmonary vasculature. Studies performed in vitro have elucidated the mechanisms underlying hypoxia-driven vascular changes. Barbera et $\mathrm{al}^{41}$ evaluated COPD patients undergoing lung resection and demonstrated that vascular changes contribute to vascular remodeling and putatively may have an effect on the vascular dynamics leading to pulmonary hypertension. Nocturnal hypoxia may induce endothelial cells to release cytokines, leading to cellular hypertrophy in the vessel wall and an increase in the extracellular matrix. In conclusion, the nocturnal hypoxic insult occurring during sleep-disordered breathing may contribute to chronic vascular remodeling, causing vascular endothelial damage and dysfunction, and increasing the risk of pulmonary hypertension in COPD. ${ }^{42}$

\section{Use of cluster analysis to define potential COPD phenotypes}

Traditionally, on the basis of specific clinical, functional, and radiological features, patients with COPD used to be classified into different biotypes, ie, the "blue bloater," in association with predominantly chronic bronchitis, and the "pink puffer," identified as predominantly emphysema. ${ }^{43}$ However, these are only two extreme phenotypes among a broader spectrum of clinical presentations in COPD. Accordingly, we propose a variation on the traditional definition of a phenotype, ie, a single disease attribute or a combination of disease attributes describing differences between individuals with COPD as they relate to clinically meaningful outcomes. It is proposed that phenotypes in COPD should have real predictive value. Studies carried out in recent years have revealed that patients with the same stage of disease may show different pathological changes, ${ }^{44,45}$ and classic COPD phenotypes clearly differ from these based on severity of emphysema as assessed by high-resolution computed tomography scanning. ${ }^{46}$

The goal of phenotyping is to identify patient groups with unique prognostic or therapeutic characteristics. However, significant variation and confusion surrounds the use of the term "phenotype" in COPD. Phenotype classically refers to any observable characteristic of an organism, and until now multiple disease characteristics have been termed COPD phenotypes. ${ }^{47}$ Evidence has shown that different COPD phenotypes may be significantly associated with differences in body mass index, health-related quality of life, ${ }^{43}$ small airways obstruction, ${ }^{45}$ and systemic inflammation. ${ }^{48}$

Cluster analysis is a collection of methods for defining groups of individuals based on measured characteristics, so that they can be grouped according to their similarities or differences into clusters. ${ }^{49,51}$ Groupings are created so that the degree of association is strong between members of the same cluster and weak between members of different clusters. ${ }^{52}$ Cluster analysis is distinct from other ways of trying to understand multivariate data, including principal component and factor analysis, discriminant analysis, and multivariate regression. The clinical relevance of cluster analysis will depend on developing diagnostic criteria to allow new individuals to be allocated into groups based on the identified clusters.

More recent work ${ }^{53}$ including that of Burgel et al, ${ }^{54}$ has used cluster analysis to characterize different types of airways disorder. The main conclusion from Burgel et al is that COPD patients with similar airflow obstruction can belong to different phenotypes, and have different symptoms (dyspnea) and outcomes (number of exacerbations and predicted mortality). At a more specific level, it is worthy of note that both Wardlaw et $\mathrm{a}^{52}$ and Weatherall et $\mathrm{a}^{53}$ have identified a cluster characterized by severe and markedly variable airflow obstruction with features of atopic asthma, chronic bronchitis, and emphysema. Patients in this phenotypic group would be unlikely to meet the inclusion criteria of the major randomized, controlled trials of either asthma ${ }^{55}$ or COPD. ${ }^{56}$ The identification of COPD phenotypes will require an iterative validation process in which candidate phenotypes are identified before their relevance to clinical outcome is determined.

\section{Classification of COPD desaturator phenotypes using cluster analysis}

COPD patients can be classified as desaturators or nondesaturators based on a $\mathrm{T}_{90}$ of $30 \%$ on polygraphic recording. 
One study ${ }^{29}$ of 51 consecutive COPD outpatients with mild daytime hypoxemia $\left(\mathrm{PaO}_{2} 60-70 \mathrm{mmHg}\right)$ identified a pattern of daytime clinical variables that distinguished desaturators from nondesaturators by using cluster analysis (see Table 1).

Considering all patients, $\mathrm{T}_{90}$, mean pulmonary artery pressure at rest, $\mathrm{PaCO}_{2}$, nadir oxygen saturation level, mean nocturnal oxygen saturation level, predicted total lung capacity, baseline oxygen saturation level awake, predicted vital capacity, and body mass index had a bimodal distribution. The variables examined in the study did not differ between men and women. Rather than using $\mathrm{T}_{90}$ alone, desaturator patients may be identified by a pattern of $\mathrm{T}_{90}(30.08 \%-45.1 \%, P=0.0001)$ mean pulmonary artery pressure $(33.1 \pm 0.7 \mathrm{mmHg}, P=0.0006)$, and $\mathrm{PaCO}_{2}$ (35.0-57.9 $\mathrm{mmHg}, P=0.0005)$ values, with the latter two variables being predictors of severity of nocturnal desaturation (see Table 2).

A hierarchical cluster analysis has been performed using these three variables, showing the highest correlation by least-squares multiple linear regression (ie, $\mathrm{T}_{90}$, mean pulmonary artery pressure, and $\mathrm{PaCO}_{2}$ ). First, we identified two major clusters of patients designated as desaturator and nondesaturators, their mean values coinciding with those of the cluster centroid. In any event, a $\mathrm{T}_{90}$ cutoff value does not appear to describe a cluster of desaturator patients adequately or to assess correctly the severity of nocturnal desaturation. Moreover, cluster analysis identifies subgroups of desaturator and nondesaturator patients who differed in degree of disease severity.

The finding that $\mathrm{T}_{90}$, mean pulmonary artery pressure, and $\mathrm{PaCO}_{2}$ were required to identify desaturator and nondesaturator patients by cluster analysis demonstrates that these variables play a predictive role. Desaturator patients have higher values for mean pulmonary artery pressure, $\mathrm{PaCO}_{2}$ and $\mathrm{T}_{90}$ than nondesaturator patients. Interestingly, cluster analysis has identified subpopulations of desaturator and nondesaturator patients, ie, two desaturator subgroups divided according to mean pulmonary artery pressure values, and two nondesaturator subgroups divided according to $\mathrm{PaCO}_{2}$ values. By reducing the distance between the elements of clusters, more clusters (or rather subdivisions) of desaturator and nondesaturator groups were obtained. ${ }^{30}$

Two subgroups, accounting for $76 \%$ of patients, were identified in the nondesaturator group, with the remaining 24\% (six of 25 patients) being comprised of scattered individual patients. The ND1 nondesaturator subgroup comprised five of 25 patients $(20 \%$; one of five women [ $20 \%$ of the subgroup]; four of five men [ $80 \%$ of the subgroup]). The centroids were as follows: $\mathrm{T}_{90}, 22.0 \%$; mean pulmonary artery pressure, $19.2 \mathrm{mmHg}$; and $\mathrm{PaCO}_{2}, 46.5 \mathrm{mmHg}$. The ND2 nondesaturator subgroup comprised 14 of 25 patients $(56 \%$; eight of 14 women [ $57.1 \%$ of the subgroup]; six of 14 men [42.9\% of the subgroup]). The centroids were as follows: $\mathrm{T}_{90}, 20.1 \%$; mean pulmonary artery pressure, $18.5 \mathrm{mmHg}$; and $\mathrm{PaCO}_{2}, 33.3 \mathrm{mmHg}$. Similarly, the desaturator group

Table I Variable mean values \pm standard errors of the mean and range of both desaturator and nondesaturator groups of COPD patient phenotypes

\begin{tabular}{|c|c|c|c|c|c|c|}
\hline \multirow[t]{2}{*}{ Variables } & \multicolumn{3}{|c|}{ Group D $(n=26)$} & \multicolumn{3}{|c|}{ Group ND $(n=25)$} \\
\hline & Mean \pm SD & Median & Range & Mean \pm SD & Median & Range \\
\hline Age (years) & $70.5 \pm 3.9$ & 71.0 & $6 I-78$ & $68.6 \pm 3.9$ & 70.0 & $59-73$ \\
\hline $\mathrm{BMI} \mathrm{kg} / \mathrm{m}^{2}$ & $31.3 \pm 2.1$ & 32.0 & $26.6-35.0$ & $29.1 \pm 3.1$ & 29.0 & $23.8-36.9$ \\
\hline $\mathrm{PaO}_{2} \mathrm{mmHg}$ & $63.5 \pm 3.4$ & 63.1 & $60.0-69.2$ & $64.9 \pm 3.4$ & 65.1 & $60.0-69.7$ \\
\hline $\mathrm{PaCO}_{2} \mathrm{mmHg}$ & $50.0 \pm 4.2$ & 50.7 & $35.1-57.9$ & $38.0 \pm 6.9$ & 34.3 & $30.2-50.9$ \\
\hline Baseline $\mathrm{SaO}_{2}$ awake (\%) & $89.9 \pm 1.9$ & 90.0 & $85.0-93.0$ & $91.3 \pm 1.40$ & 91.0 & $89.0-93.0$ \\
\hline $\mathrm{FEV}_{1}(\%$ predicted $)$ & $52.2 \pm 9.6$ & 56.8 & $35.2-65.5$ & $53.8 \pm 12.7$ & 58.1 & $33.5-68.9$ \\
\hline $\mathrm{FEV}_{1} / \mathrm{FVC}$ ratio & $40.1 \pm 3.4$ & 41.2 & $34.6-46.8$ & $34.9 \pm 2.2$ & 34.6 & $31.1-38.9$ \\
\hline TLC (\% predicted) & $107.4 \pm 7.9$ & 105.7 & $98.5-121.5$ & $98.0 \pm 6.6$ & 98.7 & $87.3-115.6$ \\
\hline Vital capacity (\% predicted) & $84.7 \pm 6.8$ & 85.9 & $68.1-98.7$ & $78.1 \pm 9.8$ & 80.6 & $62.3-98.8$ \\
\hline MPAP at rest $(\mathrm{mmHg})$ & $33.1 \pm 3.6$ & 32.0 & $28.0-40.0$ & $19.8 \pm 4.3$ & 19.0 & $16.0-37.0$ \\
\hline Mean nocturnal $\mathrm{SaO}_{2}(\%)$ & $86.6 \pm 4.1$ & 87.8 & $75.1-92.3$ & $91.6 \pm 2.1$ & 92.1 & $85.5-94.7$ \\
\hline $\mathrm{Nadir} \mathrm{SaO}_{2}(\%)$ & $78.4 \pm 7.2$ & 79.3 & $54.3-88.6$ & $86.4 \pm 2.3$ & 87.1 & $79.3-89.2$ \\
\hline $\mathrm{T}_{90}(\%)$ & $37.2 \pm 3.5$ & 37.7 & $30.8-45.5$ & $21.2 \pm 3.6$ & 22.1 & 15.2-28.4 \\
\hline $\mathrm{AHI}$, per hour of sleep & $2.9 \pm 0.8$ & 2.8 & $1.2-4.5$ & $2.7 \pm 0.7$ & 2.8 & I.I-4.I \\
\hline ESS score & $3.9 \pm 1.2$ & 4.0 & $2.0-6.0$ & $3.76 \pm 1.9$ & 4.0 & $0-7.0$ \\
\hline
\end{tabular}

Abbreviations: AHI, apnea-hypopnea index; BMI, body mass index; ESS, Epworth Sleepiness Scale; FEV , forced expiratory volume in I second; FVC, forced vital capacity; MPAP, mean pulmonary artery pressure; $\mathrm{TLC}$, total lung capacity; $\mathrm{T}_{90}$, recording time spent in bed with an oxygen saturation level $\leq 90 \% ; \mathrm{PaO}_{2}$ arterial oxygen tension; $\mathrm{PaCO}$, arterial carbon dioxide tension; $\mathrm{SaO}_{2}$ oxygen saturation; COPD, chronic obstructive pulmonary disease; $\mathrm{D}$, desaturator; ND, nondesaturator; SD, standard deviation. 
Table 2 Variables describing desaturator COPD patient phenotypes using cluster analysis

\begin{tabular}{|c|c|c|c|c|c|}
\hline \multirow[t]{2}{*}{ Variables } & \multicolumn{2}{|l|}{ Group D } & \multicolumn{2}{|l|}{ Group ND } & \multirow[t]{2}{*}{$P$ value } \\
\hline & Mean \pm SE & Range & Mean \pm SE & Range & \\
\hline $\mathrm{T}_{90}(\%)$ & $37.2 \pm 0.7$ & $30.8-45.5$ & $21.2 \pm 3.6$ & I5.2-28.4 & 0.0001 \\
\hline MPAP at rest, $\mathrm{mmHg}$ & $33.1 \pm 0.7$ & $28.0-40.0$ & $19.8 \pm 4.3$ & $16.0-37.0$ & 0.0006 \\
\hline $\mathrm{PaCO}_{2}, \mathrm{mmHg}$ & $50.0 \pm 0.8$ & $35.1-57.9$ & $38.0 \pm 6.9$ & $30.2-50.9$ & 0.0005 \\
\hline
\end{tabular}

Abbreviations: SE, standard error of the mean; MPAP, mean pulmonary artery pressure; $\mathrm{PaCO}_{2}$, arterial carbon dioxide tension; COPD, chronic obstructive pulmonary disease; D, desaturator; ND, nondesaturator.

was divided into two subgroups accounting for $88.4 \%$ of desaturator patients, with the remaining $11.5 \%$ (three of 26 patients) consisting of scattered individual patients. The D1 desaturator subgroup comprised seven of 26 patients (26.9\%, three of seven women [42.8\% of the subgroup]; four of seven men [57.2\% of the subgroup]). The centroids were as follows: $\mathrm{T}_{90}, 38.8 \%$; mean pulmonary artery pressure, $38.0 \mathrm{mmHg}$; and $\mathrm{PaCO}_{2}, 52.0 \mathrm{mmHg}$. The D2 desaturator subgroup comprised 16 of 26 patients $(61.5 \%$; five of 16 women [31.2\% of the subgroup]; 11 of 16 men [68.8\% of the subgroup]) The centroids were as follows: $\mathrm{T}_{90} 37.0 \%$; mean pulmonary artery pressure, $31.5 \mathrm{mmHg}$; and $\mathrm{PaCO}_{2} 49.9 \mathrm{mmHg}$. These data show that $\mathrm{PaCO}_{2}$ was higher in ND1 patients than in ND2 patients, and that mean pulmonary artery pressure was higher in D1 patients than in D2 patients.

Finally, cluster analysis showed that most of the subjects with higher $\mathrm{PaCO}_{2}$ values were men in the small ND1 subgroup. This applies also to the D2 subgroup, but the men in this subgroup had lower levels of mean pulmonary artery pressure levels than the women.

Further studies are required to understand the importance of these findings. They provide a naturalistic classification that, if confirmed in other studies, could be developed into a modified taxonomy for disorders of sleep-related breathing disturbances in COPD. In conclusion, ${ }^{30}$ this cluster analysis showed that clustered COPD desaturator patients can be identified not by $\mathrm{T}_{90}$ value alone, but by a pattern of $\mathrm{T}_{90}$, mean pulmonary artery pressure, and $\mathrm{PaCO}_{2}$ values, and that the latter two variables are predictors of the severity of nocturnal desaturation.

Awake desaturator patients have lower $\mathrm{PaO}_{2}$ and higher $\mathrm{PaCO}_{2}$ values than awake nondesaturator patients. ${ }^{57}$ Moreover, daytime hypercapnia is a risk factor for nocturnal hypoxemia in COPD patients with mild daytime hypoxemia. ${ }^{58}$

The degree of airways obstruction in COPD patients, as measured by forced expiratory volume in 1 second $\left(\mathrm{FEV}_{1}\right)$ /forced vital capacity, can correlate with the risk of prolonged hypoxemia, ${ }^{59}$ which appears to increase the morbidity and mortality risk in these patients, although the exact mechanism(s) that account for this increased risk are not well understood. The increased risk of death may be due to more prolonged hypoxia, although night-time hypercapnia is probably also greater. There is also increasing evidence that COPD has systemic consequences. Inflammation is caused via various mediators (tumor necrosis factor alpha, interleukin-6, and interleukin-8), in addition to the oxidative stress. The review by McNicholas shows how the disease acts through similar pathways to cause cardiovascular disease. ${ }^{60}$ Another intriguing possibility mentioned in that review is that nocturnal desaturation in COPD may contribute to an increased incidence of COPD exacerbations, which may accelerate the decline in lung function and be associated with greater mortality. ${ }^{61,62}$

Further cluster analyses, both population-based and clinic-based, will contribute to greater understanding of the true patterns of airway disorders. The clinical application of cluster analysis will depend on developing diagnostic criteria to allow new individuals to be allocated to groups based on identified clusters.

\section{Diagnosis}

The Global Initiative for Chronic Obstructive Lung Disease $(G O L D)^{1}$ guidelines suggest that patients with relatively mild COPD and evidence of pulmonary hypertension and diurnal hypercapnia should be referred for overnight testing. This recommendation reflects data collected by Chaouat et $\mathrm{al}^{66}$ and Toraldo et $\mathrm{al}^{30}$ and emphasized by Kessler, ${ }^{35}$ ie, in all COPD patients with obesity, higher diurnal $\mathrm{PaCO}_{2}$ reflects increased muscle load in those with both increased upper and lower airway resistance. It is necessary to perform the following examinations: ${ }^{30}$ static lung volumes measured by body plethysmography and dynamic lung volumes by mass flow sensors in seated patients according to standard procedures; arterial blood gases measured at the radial artery using microelectrodes in seated patients spontaneously breathing air; resting mean daytime pulmonary artery pressure measured by color 
Doppler echocardiography; and nocturnal desaturation evaluated by polygraphic recording of oxygen saturation, snoring, air flow, thoracic and abdominal respiratory movements, heart rate, including an electrocardiogram in real-time mode; and body position.

In our research, patients with a history of loud snoring and excessive daytime sleepiness, as evaluated by the Epworth Sleepiness Scale (range 0-10) and with an apnea-hypopnea index $\geq 5$ per hour were excluded because of suspected obstructive sleep apnea syndrome. We also excluded patients in whom mean pulmonary artery pressure could not be evaluated by color Doppler echocardiography. Finally, quantitative assessment of emphysema by computed tomography scanning offers an objective measure of parenchymal disease that correlates well with histopathologic findings and is predictive of the degree of expiratory airflow obstruction. Objective measures of proximal airway wall thickening obtained via computed tomography are inversely correlated with lung function and relate to burden of small airway disease and exacerbation frequency.

\section{Treatment}

Management options for patients with sleep-related respiratory disturbances include general measures, such as optimizing therapy for the underlying condition and supplemental oxygen, in addition to pharmacological therapy. We propose that COPD phenotypes should be associated with clinically meaningful outcomes. Such a more focused definition makes possible a classification of patients into distinct prognostic and therapeutic subgroups for both clinical and research purposes. The goal of treatment is to maintain adequate oxygenation at all times and to prevent sleep-disordered breathing. Supplemental oxygen is the mainstay of treatment for those with daytime and nocturnal hypoxemia, and has been shown to reduce overall mortality if used for more than 18 hours per day, including during sleep. ${ }^{63,64}$

It may be that COPD patients with hypoxemia are at increased risk of mortality only during sleep, compared with those who are not, although this finding is only based on a single study of retrospective data. ${ }^{65}$ Again, correction of nocturnal hypoxemia alone (in patients with daytime normoxia) does not seem to improve pulmonary hemodynamics or mortality to a significant extent, ${ }^{66,67}$ although it may improve sleep quality and is frequently prescribed. ${ }^{68}$

A Cochrane analysis ${ }^{69}$ determined the effect of domiciliary oxygen on survival in COPD and identified six relevant randomized controlled trials. There was no effect on survival during 3 years of follow-up in patients with mild to moderate hypoxemia and those with only arterial desaturation at night. Home oxygen improved survival only in patients with $\mathrm{PaO}_{2} \leq 60 \mathrm{mmHg}$.

Controversy exists as to whether continuous positive airway pressure (CPAP) therapy improves daytime lung function in patients with stable COPD. At least in an animal model, upper airways irritation increased lower airway resistance, so, in theory, correction of repetitive airway collapse might improve pulmonary function. ${ }^{70}$ Others have postulated that offloading the respiratory muscles could decrease hypoventilation, oxygen consumption, and carbon dioxide production by the respiratory muscles. These muscles may be rested by CPAP, given that it prevents the increase in upper airway resistance occurring during sleep. Alternatively, CPAP may offset intrinsic positive end-expiratory pressure in severe COPD. Mezzanotte et al used CPAP for 1-3 weeks in eight patients with COPD and assessed inspiratory force and endurance. They found significant improvements in maximum inspiratory force and performance on a 12-minute walk test. ${ }^{71}$ Improvements have also been observed in daytime oxygenation and hypercapnia. ${ }^{72,73}$

Long-term nocturnal noninvasive ventilation can also be considered in COPD patients with chronic respiratory failure, with improvements in gas exchange during wakefulness having been reported, ${ }^{74}$ in addition to improvements in respiratory muscle strength and endurance. ${ }^{75}$ Sleep quality and diurnal $\mathrm{PaO}_{2}$ and $\mathrm{PaCO}_{2}$ levels are better with noninvasive ventilation plus supplemental oxygen than with supplemental oxygen alone. ${ }^{76}$ There has been considerable interest in the use of noninvasive ventilation in stable hypercapnic COPD, with multiple studies and inconsistent results over the years. ${ }^{77}$ Several mechanisms are likely to play a role in these improvements, including rest of chronically fatigued respiratory muscles, thereby improving daytime respiratory muscle function. ${ }^{78}$

Two recent studies warrant attention. The first was a randomized controlled trial of noninvasive ventilation in patients with stable hypercapnic COPD by McEvoy et al, which showed significant improvement in adjusted mortality ${ }^{79}$ There was little or no change in pulmonary function or daytime blood gases. The improvement in mortality using noninvasive ventilation was associated with a worse quality of life, which tempers enthusiasm for this approach. A second report by Windisch et al reported a reduction in mortality with noninvasive ventilation, although only used historical controls. However, these authors used what they called "high-intensity noninvasive ventilation," with a very high driving pressure (average inspiratory pressure $28 \mathrm{~cm} \mathrm{H}_{2} \mathrm{O}$, average expiratory pressure $5 \mathrm{~cm} \mathrm{H}_{2} \mathrm{O}$ ) and a high respiratory rate (about 21 breaths per minute). With 
Table 3 Management options for chronic obstructive pulmonary disease desaturator phenotype patients with sleep-related hypoxemia and/or hypercapnia

Optimize overall therapy of COPD

Prompt therapy of infective exacerbations

Supplemental oxygen therapy $\geq 2 \mathrm{~L} /$ minute when indicated (long-term oxygen therapy)

Noninvasive positive pressure ventilation particularly during acute exacerbations

Noninvasive positive pressure ventilation if $\mathrm{PaCO}_{2} 50 \%-54 \%$ with hospitalization related to recurrent episodes of hypercapnic respiratory failure

( $\geq 2$ in a 12-month period)

Noninvasive positive pressure ventilation if $\mathrm{PaCO}_{2} 50 \%-54 \%$ with nocturnal desaturation $\left(\mathrm{SaO}_{2} \leq 88 \%\right.$ for five continuous minutes while receiving oxygen therapy $\geq 2 \mathrm{~L} /$ minute)

Pharmacological therapy and bronchodilators, usually salmeterol, and particularly anticholinergics (ipratropium, tiotropium, and aclidinium bromide)

Theophylline

Multichannel sleep study to exclude associated OSA syndrome if clinically indicated

CPAP/BiPAP if "overlap syndrome" (COPD and OSA)

Abbreviations: $\mathrm{CPAP}$, continuous positive airways pressure; $\mathrm{PaCO}_{2}$, arterial carbon dioxide tension; OSA, obstructive sleep apnea; COPD, chronic obstructive pulmonary disease; BiPAP, bilevel positive airway pressure.

those settings, requiring hospital acclimatization, there were improvements in spirometry and blood gas abnormalities. ${ }^{80}$

\section{Weight loss}

Weight loss can clearly be beneficial in obese COPD patients with a desaturator phenotype. ${ }^{81}$ However, in COPD, weight loss has generally been associated with increased mortality, because cachexia sets in with increasing disease severity. Thus, there are no data to recommend weight loss as a therapeutic option in those with the COPD desaturator phenotype, although it seems reasonable that those with less severe COPD would benefit from dietary and respiratory rehabilitation.

\section{Bronchodilators and corticosteroids}

Treatment of the underlying obstructive lung disease is helpful in preventing or ameliorating nocturnal oxygen desaturation in patients with COPD. Data exist for the cholinergic bronchodilators, ipratropium and tiotropium. Martin et al studied the effect of ipratropium inhaled four times a day in 36 patients with moderate to severe COPD $\left(\mathrm{FEV}_{1} \leq 65 \%\right.$ predicted). ${ }^{82}$ After 4 weeks, nocturnal oxygen saturation improved, subjective sleep quality was better, and there was an increase in total REM sleep time. Tiotropium also improved nocturnal oxygen saturation, although sleep quality was not affected. ${ }^{83} \mathrm{~A}$ recent study with aclidinium bromide, a novel long-acting antimuscarinic drug, investigated its potential effects on night-time symptoms in COPD. This study showed that the improvement in lung function obtained by administration of aclidinium bromide $400 \mathrm{mg}$ twice daily translated into symptomatic benefits in COPD patients, especially during sleep and in the early morning. ${ }^{84}$ Long-acting $\beta$-agonists, such as salmeterol, show similar benefits. ${ }^{85}$ Oral steroid therapy in stable COPD improves nocturnal oxygen desaturation and increases total sleep time. ${ }^{86}$ Although there are no relevant data, we might expect a similar improvement with inhaled corticosteroids. Taken together, the data suggest that treatment of COPD with or without hypercapnia will ameliorate nocturnal oxygen desaturation, and may decrease the need for supplemental oxygen as well as noninvasive ventilation. In Table 3, we outline some suggested management options for COPD patients with the desaturator phenotype who have sleep-related hypoxemia and/or hypercapnia.

\section{Conclusion and future perspectives}

Cluster analysis may prove useful in COPD phenotyping. Although the goal of cluster analysis is to reduce the number of observations or cases by grouping them into a smaller set of clusters, the goal of factor analysis is to reduce the number of variables by grouping them into a smaller set of factors. However, these types of analyses would still require longitudinal validation to determine how such clustered subjects differ in terms of important clinical outcomes. In addition, such analyses may or may not ultimately be useful in defining specific biologic pathways or therapies.

From a practical standpoint, validation of phenotypes in COPD will require longitudinal data collection in carefully characterized patient populations. Studies such as ECLIPSE (Evaluation of COPD Longitudinally to Identify Predictive Surrogate Endpoints), that are systematically gathering clinical, physiological, radiological, biological, and genetic data on COPD subjects, will aid in this regard. ${ }^{87}$

Our study, albeit in only 51 patients, describes a statistical methodology allowing the identification of clinical COPD desaturator phenotypes. This study shows that desaturator 
patients can be identified not by their $T_{90}$ value alone but by a pattern of $\mathrm{T}_{90}$, mean pulmonary artery pressure, and $\mathrm{PaCO}_{2}$ values, and that the latter two variables are predictors of the severity of nocturnal desaturation. In any event, $\mathrm{a} \mathrm{T}_{90}$ cutoff value does not appear to describe desaturator patients adequately or to assess the severity of nocturnal desaturation correctly. Moreover, cluster analysis identified subgroups of desaturator and nondesaturator patients who differ in their degree of disease severity.

We propose that dissemination of this original approach could result in better phenotypic characterization, which may prove useful in both clinical practice and in clinical trials. We further propose that data from large clinical trials should be reanalyzed using this methodology for classification of patients according to their clinical characteristics at study entry. These preliminary data would provide a clear rationale for further clinical studies. The priority would then be to determine whether the phenotypes vary in their response to different pharmacological treatments. This knowledge could lead to treatment specifically targeted at defined phenotypic groups, rather than asthma or COPD in general, which is the current management approach. Ultimately, whether different treatment strategies would provide different outcomes for these groups will confirm or refute the clinical value of cluster analysis. This knowledge could lead to different pharmacological treatments and other interventions directed at specific phenotypic groups. ${ }^{88}$ We consider that achieving this goal is worthy of the research endeavor.

\section{Acknowledgments}

The authors would like to acknowledge Lubello Roberto, Legari Giulia, D’Andrea Agostino, and Fausto Meleleo, for their excellent technical assistance. The authors also thank Franca Carbonaro, translator, for editing this article.

\section{Disclosure}

The authors declare that they do not have any conflicts of interest or financial relationship with any commercial entity mentioned in this work.

\section{References}

1. Rabe KF, Hurd S, Anzueto A, et al. Global strategy for the diagnosis, management, and prevention of chronic obstructive pulmonary disease: GOLD executive summary. Am J Respir Crit Care Med. 2007; 176:532-555.

2. Agusti AG. COPD, a multicomponent disease: implications for management. Respir Med. 2005;99:670-682.

3. Barnes PJ, Celli BR. Systemic manifestations and comorbidities of COPD. Eur Respir J. 2009;33:1165-1185.

4. Chatila WM, Thomashow BM, Minai OA, et al. Comorbidities in chronic obstructive pulmonary disease. Proc Am Thorac Soc. 2008;5:549-555.
5. Gan WQ, Man SF, Senthilselvan A, et al. Association between chronic obstructive pulmonary disease and systemic inflammation: a systematic review and a meta-analysis. Thorax. 2004;59:574-580.

6. Pinto-Plata VM, Mullerova $\mathrm{H}$, Toso JF, et al. C-reactive protein in patients with COPD, control smokers and non-smokers. Thorax. 2006;61:23-28.

7. Fabbri LM, Rabe KF. From COPD to chronic systemic inflammatory syndrome? Lancet. 2007;370:797-799.

8. Fabbri LM, Luppi F, Beghe B, et al. Complex chronic comorbidities of COPD. Eur Respir J. 2008;31:204-212.

9. Broekhuizen R, Wouters EF, Creutzberg EC, et al. Raised CRP levels mark metabolic and functional impairment in advanced COPD. Thorax. 2006;61:17-22.

10. de Torres JP, Cordoba-Lanus E, Lopez-Aguilar C, et al. C-reactive protein levels and clinically important predictive outcomes in stable COPD patients. Eur Respir J. 2006;27:902-907.

11. Watz H, Waschki B, Kirsten A, et al. The metabolic syndrome in patients with chronic bronchitis and COPD: frequency and associated consequences for systemic inflammation and physical inactivity. Chest. 2009;136:1039-1046.

12. Peleman RA, Rytila PH, Kips JC, et al. The cellular composition of induced sputum in chronic obstructive pulmonary disease. Eur Respir J. 1999;13:839-843.

13. Turato G, Zuin R, Miniati M, et al. Airway inflammation in severe chronic obstructive pulmonary disease: relationship with lung function and radiologic emphysema. Am J Respir Crit Care Med. 2002;166:105-110.

14. Baraldo S, Turato G, Badin C, et al. Neutrophilic infiltration within the airway smooth muscle in patients with COPD. Thorax. 2004;59:308-312.

15. Roy K, Smith J, Kolsum U, et al. COPD phenotype description using principal components analysis. Respir Res. 2009;10:41-42.

16. Takabatake N, Nakamura $\mathrm{H}$, Abe $\mathrm{S}$, et al. The relationship between chronic hypoxemia and activation of the tumour necrosis factor-alpha system in patients with chronic obstructive pulmonary disease. Am J Respir Crit Care Med. 2000;161:1179-1184.

17. Yu AY, Frid MG, Shimoda LA, et al. Temporal, spatial, and oxygenregulated expression of hypoxia-inducible factor-1 in the lung. Am J Physiol. 1998;275:L818-L826.

18. Eagan TM, Ueland T, Wagner PD, et al. Systemic inflammatory markers in COPD: results from the Bergen COPD Cohort Study. Eur Respir J. 2010;35:540-548.

19. Kinsman RA, Yaroush RA, Fernandez E, et al. Symptoms and experiences in chronic bronchitis and emphysema. Chest. 1983;83:755-761.

20. Klink ME, Dodge R, Quan SF. The relation of sleep complaints to respiratory symptoms in a general population. Chest. 1994;105:151-154.

21. Douglas NJ, White DP, Pickett CK, et al. Respiration during sleep in normal man. Thorax. 1982;37:840-844.

22. Douglas NJ, White DP, Weil JV, et al. Hypoxic ventilatory response decreases during sleep in normal men. Am Rev Respir Dis. 1982;125:286-289.

23. Douglas NJ. Control of ventilation during sleep. Clin Chest Med. 1985;6:563-575.

24. Collop N. Sleep and sleep disorders in chronic obstructive pulmonary disease. Respiration. 2010;80(1):78-86.

25. Fletcher E, Miller J, Divine G, et al. Nocturnal oxyhemoglobin desaturation in COPD patients with arterial oxygen tensions above $60 \mathrm{mmHg}$. Chest. 1987;92:604-608.

26. Johnson MW, Remmers JE. Accessory muscle activity during sleep in chronic obstructive pulmonary disease. J Appl Physiol. 1984;57:1011-1017.

27. Hudgel DW, Martin RJ, Capehart M, et al. Contribution of hypoventilation to sleep oxygen desaturation in chronic obstructive pulmonary disease. J Appl Physiol. 1983;55:669-677.

28. Connaughton JJ, Caterall JR, Elton RA, et al. Do sleep studies contribute to the management of patients with severe chronic obstructive pulmonary disease? Am Rev Respir Dis. 1988;138:341-344. 
29. Bradley TD, Mateika J, Li D, Avenado M, et al. Daytime hypercapnia in the development of nocturnal hypoxemia in COPD. Chest. 1990;97:308-312.

30. Toraldo DM, Nicolardi G, De Nuccio F, et al. Pattern of variables describing desaturator COPD patients, as revealed by cluster analysis. Chest. 2005;128:3828-3837.

31. Becker HF, Piper AJ, Flynn WE, et al. Breathing during sleep in patients with nocturnal desaturation. Am J Respir Crit Care Med. 1999;159:112-118.

32. O'Donoghue FJ, Catcheside PG, Eckert DJ, et al. Changes in respiration in NREM sleep in hypercapnic chronic obstructive pulmonary disease. J Physiol. 2004;559(Pt 2):663-673.

33. Naeije R. Pulmonary hypertension and right heart failure in chronic obstructive pulmonary disease. Proc Am Thorac Soc. 2005;2:20-22.

34. Galiè N, Hoeper MM, Humbert M, et al. Guidelines for the diagnosis and treatment of pulmonary hypertension. Eur Respir $J$. 2009;34:1219-1263.

35. Kessler R, Faller M, Weitzenblum E, et al. "Natural history" of pulmonary hypertension in a series of 131 patients with chronic obstructive lung disease. Am J Respir Crit Care Med. 2001;164:219-224.

36. Fletcher EC, Luckett RA, Miller T, et al. Pulmonary vascular hemodynamics in chronic lung disease patients with and without oxyhemoglobin desaturation during sleep. Chest. 1989;95:757-764.

37. Douglas NJ, White DP, Weil JV, et al. Hypercapnic ventilatory response in sleeping adults. Am Rev Respir Dis. 1982;126:758-762.

38. McNicholas WT, Fitzgerald MX. Nocturnal deaths among patients with chronic bronchitis and emphysema. $\mathrm{Br}$ Med J (Clin Res Ed). 1984;289:878.

39. Mal H. Prevalence and diagnosis of severe pulmonary hypertension in patients with chronic obstructive pulmonary disease. Curr Opin Pulm Med. 2007;13:114-119.

40. Lavie L. Obstructive sleep apnoea syndrome - an oxidative stress disorder. Sleep Med Rev. 2003;7:35-51.

41. Barbera JA, Riverola A, Roca J, et al. Pulmonary vascular abnormalities and ventilation-perfusion relationships in mild chronic obstructive pulmonary disease. Am J Respir Crit Care Med. 1994;149:423-429.

42. Jyothula S, Safdar Z. Update on pulmonary hypertension complicating chronic obstructive pulmonary disease. Int J Chron Obstruct Pulmon Dis. 2009;4:351-363.

43. Johnson MA, Woodcock, Rehahn M, et al. Are "pink puffers" more breathless than "blue bloaters"? Br Med J (Clin Res Ed). 1983;286:179-182.

44. Makita H, Nasuhara Y, Nagai K, et al. Characterisation of phenotypes based on severity of emphysema in chronic obstructive pulmonary disease. Thorax. 2007;62:932-937.

45. Fujimoto K, Kitaguchi Y, Kubo K, et al. Clinical analysis of chronic obstructive pulmonary disease phenotypes classified using high resolution computed tomography. Respirology. 2006;11:731-740.

46. Kitaguchi Y, Fujimoto K, Kubo K, et al. Characteristics of COPD phenotypes classified according to the findings of HRCT. Respir Med. 2006;100:1742-1752.

47. Han MK, Agusti A, Calverley PM, et al. Chronic obstructive pulmonary disease phenotypes: the future of COPD. Am J Respir Crit Care Med. 2010;182:598-604.

48. Izquierdo JL, Almonacid C, Parra T, et al. Systemic and lung inflammation in 2 phenotypes of chronic obstructive pulmonary disease. Arch Bronconeumol. 2006;42:332-337.

49. Everitt R. An R and S-Plus Companion to Multivariate Analysis. London, UK: Springer-Verlag; 2005.

50. Khattree R, Naik DN. Multivariate Data Reduction and Discrimination with SAS Software. Cary, NC: SAS Institute; 2000.

51. McLachlan GJ. Cluster analysis and related techniques in medical research. Stat Methods Med Res. 1992;1:27-48.

52. Wardlaw A, Silverman M, Siva R, et al. Multi-dimensional phenotyping: towards a new taxonomy for airway disease. Clin Exp Allergy. 2005;35:1254-1262.
53. Weatherall M, Travers J, Shirtcliffe PM, et al. Distinct clinical phenotypes of airways disease defined by cluster analysis. Eur Respir J. 2009;34:812-818.

54. Burgel P-R, Paillasseur J-L, Caillaud D, et al. Clinical COPD phenotypes: a novel approach using principal component and cluster analyses. Eur Respir J. 2010;36:531-539.

55. Travers J, Marsh S, Williams M, et al. External validity of randomised controlled trials in asthma: to whom do the results of the trials apply? Thorax. 2007;62:219-223.

56. Travers J, Marsh S, Caldwell B, et al. External validity of randomized controlled trials in COPD. Respir Med. 2007;101:1313-1320.

57. Fletcher EC, Scott D, Quian W, et al. Evolution of nocturnal oxyhemoglobin desaturation in patients with chronic obstructive pulmonary disease and daytime $\mathrm{PaO}_{2}$ above $60 \mathrm{mmHg}$. Am Rev Respir Dis. 1991;144:401-404.

58. Levi-Valensi P, Weitzenblum E, Rida Z, et al. Sleep-related oxygen desaturation and daytime pulmonary haemodynamics in COPD patients. Eur Respir J. 1992;5:301-307.

59. Sanders MH, Newman AB, Haggerty CL, et al. Sleep and sleepdisordered breathing in adults with predominantly mild obstructive airway disease. Am J Respir Crit Care Med. 2003;167:7-14.

60. McNicholas WT. Chronic obstructive pulmonary disease and obstructive sleep apnea: overlaps in pathophysiology, systemic inflammation, and cardiovascular disease. Am J Respir Crit Care Med. 2009;180:692-700.

61. Donaldson GC, Seemungal TA, Bhowmik A, Wedzicha JA. Relationship between exacerbation frequency and lung function decline in chronic obstructive pulmonary disease. Thorax. 2002;57:847-852.

62. Soler-Cataluna JJ, Martinez-Garcia MA, Roman Sanchez P, Salcedo E, Navarro M, Ochando R. Severe acute exacerbations and mortality in patients with chronic obstructive pulmonary disease. Thorax. 2005;60:925-931.

63. Continuous or nocturnal oxygen therapy in hypoxemic chronic obstructive lung disease: a clinical trial. Nocturnal Oxygen Therapy Trial Group. Ann Intern Med. 1980;93:391-398.

64. Long term domiciliary oxygen therapy in chronic hypoxic cor pulmonale complicating chronic bronchitis and emphysema. Report of the Medical Research Council Working Party. Lancet. 1981;1:681-686.

65. Fletcher EC, Donner CF, Midgren B, et al. Survival in COPD patients with a daytime $\mathrm{PaO}_{2}$ greater than $60 \mathrm{mmHg}$ with and without nocturnal oxyhemoglobin desaturation. Chest. 1992;101:649-655.

66. Chaouat A, Weitzenblum E, Kessler R, et al. A randomized trial of nocturnal oxygen therapy in chronic obstructive pulmonary disease patients. Eur Respir J. 1999;14:1002-1008.

67. Fletcher EC, Luckett RA, Goodnight-White S, Miller CC, Qian W, Costarangos-Galarza C. A double-blind trial of nocturnal supplemental oxygen for sleep desaturation in patients with chronic obstructive pulmonary disease and a daytime $\mathrm{PaO}_{2}$ above $60 \mathrm{mmHg}$. Am J Rev Respir Dis. 1992;145:1070-1076.

68. Calverley PM, Brezinova V, Douglas NJ, Catterall JR, Flenley DC. The effect of oxygenation on sleep quality in chronic bronchitis and emphysema. Am Rev Respir Dis. 1982;126(2):206-210.

69. Cranston J, Crockett A, Moss J, Alpers J, Cranston J. Domiciliary oxygen for chronic obstructive pulmonary disease. Cochrane Database Syst Rev. 2005;4:CD001744.

70. Nadel JA, Widdicombe JG. Reflex effects of upper airway irritation on total lung resistance and blood pressure. J Appl Physiol. 1962;17: 861-865.

71. Mezzanotte WS, Tangel DJ, Fox AM, Ballard RD, White DP. Nocturnal nasal continuous positive airway pressure in patients with chronic obstructive pulmonary disease: influence on waking respiratory muscle function. Chest. 1994;106:1100-1108.

72. Mansfield D, Naughton MT. Effects of continuous positive airway pressure on lung function in patients with chronic obstructive pulmonary disease and sleep disordered breathing. Respirology. 1999;4:365-370. 
73. Sforza E, Krieger J, Weitzenblum E, Apprill M, Lampert E, Ratamaharo J. Long-term effects of treatment with nasal continuous positive airway pressure on daytime lung function and pulmonary hemodynamics in patients with obstructive sleep apnea. Am Rev Respir Dis. 1990;141(4 Pt 1):866-870.

74. Elliott MW, Mulvey DA, Moxham J, Green M, Branthwaite MA. Domiciliary nocturnal nasal intermittent positive pressure ventilation in COPD: mechanisms underlying changes in arterial blood gas tensions. Eur Respir J. 1991;4:1044-1052.

75. Goldstein RS, De Rosie JA, Avendano MA, Dolmage TE. Influence of noninvasive positive pressure ventilation on inspiratory muscles. Chest. 1991;99:408-415.

76. Meecham Jones DJ, Paul EA, Jones PW, Wedzicha JA. Nasal pressure support ventilation plus oxygen compared with oxygen therapy alone in hypercapnic COPD. Am J Respir Crit Care Med. 1995;152:538-544.

77. Kolodziej MA, Jensen L, Rowe B, Sin D. Systematic review of noninvasive positive pressure ventilation in severe stable COPD. Eur Respir J. 2007;30:293-306.

78. Renston JP, Di Marco AF, Supinski GS. Respiratory muscle rest using nasal BiPAP ventilation in patients with stable severe COPD. Chest. 1994;105:1053-1060.

79. McEvoy RD, Pierce RJ, Hillman D, et al. Nocturnal non-invasive nasal ventilation in stable hypercapnic COPD: a randomised controlled trial. Thorax. 2009;64:561-566.

80. Windisch W, Haenel M, Storre JH, Dreher M. High-intensity noninvasive positive pressure ventilation for stable hypercapnic COPD. Int J Med Sci. 2009;6:72-76.
81. Poulain M, Doucet M, Major GC, et al. The effect of obesity on chronic respiratory diseases: pathophysiology and therapeutic strategies. CMAJ. 2006;174:1293-1299.

82. Martin RJ, Bartelson BL, Smith P, et al. Effect of ipratropium bromide treatment on oxygen saturation and sleep quality in COPD. Chest. 1999;115:1338-1345.

83. Kerwin E, Rennard SI, Gelb AF, et al. Twice-daily aclidinium bromide in COPD patients: night-time symptoms and rescue medication use in ACCORD COPD I. Am J Respir Crit Care Med. 2011;183:A1592.

84. McNicholas WT, Calverley PM, Lee A, Edwards JC. Long-acting inhaled ant cholinergic therapy improves sleeping oxygen saturation in COPD. Eur Respir J. 2004;23:825-831.

85. Ryan S, Doherty LS, Rock C, Nolan GM, McNicholas WT. Effects of salmeterol on sleeping oxygen saturation in chronic obstructive pulmonary disease. Respiration. 2010;79:475-481.

86. Sposato B, Mariotta S, Palmiero G, Ricci A, Gencarelli G, Franco C. Oral corticosteroids can improve nocturnal isolated hypoxemia in stable COPD patients with diurnal $\mathrm{PaO}_{2} \leq 60 \mathrm{mmHg}$. Eur Rev Med Pharmacol Sci. 2007;11:365-372.

87. Agusti A, Calverley PMA, Celli B, et al. Characterization of COPD heterogeneity in the Eclipse cohort. Respir Res. 2010;11:122.

88. Beasley R, Weatherall M, Travers J, et al. Time to define the disorders that make up the syndrome of COPD. Lancet. 2009;374:670-672.
International Journal of COPD

\section{Publish your work in this journal}

The International Journal of COPD is an international, peer-reviewed journal of therapeutics and pharmacology focusing on concise rapid reporting of clinical studies and reviews in COPD. Special focus is given to the pathophysiological processes underlying the disease, intervention programs, patient focused education, and self management protocols.

\section{Dovepress}

This journal is indexed on PubMed Central, MedLine and CAS. The manuscript management system is completely online and includes a very quick and fair peer-review system, which is all easy to use. Visit http://www.dovepress.com/testimonials.php to read real quotes from published authors. 